\title{
Robotic Heller myotomy
}

\author{
Zachary W. Sollie ${ }^{1}$, Alisha Z. Jiwani², Benjamin Wei ${ }^{2}$ \\ 'University of Alabama School of Medicine, Birmingham, AL 35233, USA. \\ ${ }^{2}$ Division of Cardiothoracic Surgery, University of Alabama Birmingham, Birmingham, AL 35294, USA.
}

Correspondence to: Dr. Benjamin Wei, Division of Cardiothoracic Surgery, University of Alabama Birmingham, Zeigler Research Building 707, 703 19th Street South, Birmingham, AL 35294, USA. E-mail: bwei@uab.edu

How to cite this article: Sollie ZW, Jiwani AZ, Wei B. Robotic Heller myotomy. Mini-invasive Surg 2020;4:80. http://dx.doi.org/10.20517/2574-1225.2020.81

Received: 7 Aug 2020 First Decision: 14 Sep 2020 Revised: 23 Sep 2020 Accepted: 24 Sep 2020 Published: 6 Nov 2020

Academic Editor: Noriyoshi Sawabata Copy Editor: Cai-Hong Wang Production Editor: Jing Yu

\begin{abstract}
Achalasia is a neurodegenerative disorder of the esophagus of unknown etiology, which affects motility, causing symptoms such as progressive dysphagia with liquids then solids, heartburn, regurgitation, odynophagia, weight loss, nocturnal cough, and chest pain. Evaluation will show a characteristic "bird's beak" appearance on barium esophagram and diagnosis is confirmed with esophageal manometry. Durable relief from the symptoms of achalasia can be achieved with pneumatic dilation, per-oral endoscopic myotomy, or surgical myotomy. Laparoscopic Heller myotomy with Dor (or Toupet) fundoplication for many years had been considered the gold standard for therapy. Since its development in 2001, the robotic Heller myotomy (RHM) has gained increasing popularity. Studies have shown equivalent efficacy of relieving achalasia symptoms but decreased incidence of esophageal perforation with RHM. The higher cost of RHM remains the largest barrier. Our objective was to provide a brief review of the current literature related to RHM and provide a detailed description of how to perform the procedure.
\end{abstract}

Keywords: Heller myotomy, achalasia, robotic, surgical treatments for achalasia, minimally invasive surgery

\section{INTRODUCTION}

Achalasia is a neurodegenerative disorder of the esophagus characterized by failure of the lower esophageal sphincter (LES) to relax and decrease or absence of esophageal body peristalsis ${ }^{[1-3]}$. The incidence has variable reports, but meta-analysis estimates that it affects 0.5 to 1.2 persons per 100,000 per year ${ }^{[3,4]}$ Achalasia can affect both genders, all races and all ages. A few studies have suggested that disease risk increases

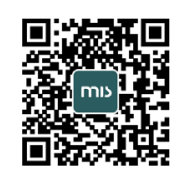


age, whereas other studies describe a bimodal incidence by age with peaks around ages 30 and 60 years ${ }^{[1-6]}$. The etiology of achalasia remains unclear, although it is purported to be multifactorial. The most common form of achalasia is idiopathic.

Although rare, achalasia is likely the best described primary esophageal motility disorder with clear clinical, manometric, endoscopic and radiologic findings ${ }^{[2,3]}$. Commonly reported symptoms associated with achalasia include progressive dysphagia with liquids and then solids, heartburn, regurgitation, odynophagia, weight loss, nocturnal cough and chest pain. Manometry is the gold standard for diagnosis of achalasia into 3 subtypes with different manometric patterns: Type I (classic achalasia of aperistalsis and failure of the LES to relax), Type II (with esophageal compression) and Type III (spastic achalasia) as defined by the Chicago classification ${ }^{[3,7]}$. Endoscopy will demonstrate food particles in the absence of a mucosal stricture and a narrowed gastroesophageal junction, the latter of which is well learned as the "bird's beak" appearance on barium esophagram ${ }^{[3,7]}$.

The treatment of achalasia is not curative. It is a progressive disease that leads patients to seek symptom palliation, which can be accomplished by reducing the resting and swallow-induced pressures of the LES $^{[1,3,7-10]}$. That is, therapy is aimed at relieving the functional obstruction. This can be done with medical, endoscopic and surgical therapies. Medical therapies include drugs such as nitrates and calcium channel blockers that act to relax smooth muscle ${ }^{[3,7]}$. Endoscopic sphincteric injection of Botox has also been performed with limited and variable success rates, whereas graded pneumatic dilation has more robust results $^{[7,11]}$. In comparison, minimally invasive Heller myotomy is currently the gold standard surgical approach for achalasia as it has the best long-term outcome. Although per-oral endoscopic myotomy (POEM) and robotic Heller myotomy (RHM) are increasingly being used, laparoscopic Heller myotomy $(\mathrm{LHM})$ is the longest practiced surgical approach with safe and effective outcomes ${ }^{[8,9,12-15]}$.

With recent advancements in technology, RHM has become an alternative option for the treatment of achalasia. It was first described in 2001 in a case report by Melvin et al. ${ }^{[16]}$. At this point, outcomes are somewhat controversial for RHM compared to LHM; however, many studies report that it is equivalent to LHM in terms of achieving the desired result of symptomatic relief but with fewer complications related to mucosal perforation ${ }^{[9,13,14,17-20]}$. Cost remains one of the largest barriers to overcome in robotic operations; however, cost reduction strategies can be further explored with increased utilization ${ }^{[10,17,19,21]}$.

\section{ROBOTIC HELLER MYOTOMY AND PARTIAL FUNDOPLICATION}

\section{Perioperative preparation, positioning and port placement}

The patient is placed supine on the operating room table with both arms tucked at the sides. Foot boards should be secured at the end of the table to prevent the patient from sliding down the table. A dose of perioperative antibiotics (first-generation cephalosporin) is administered within $1 \mathrm{~h}$ of incision. After induction with general anesthesia, a single-lumen endotracheal tube is used for intubation. Upper endoscopy is then performed and the scope left in the stomach with the light turned off. The patient's abdomen is then prepped and draped in a sterile manner.

The Da Vinci Xi surgical system (Intuitive Surgical Inc., Sunnyvale, CA, USA) is used for our operation. A total of 5 or 6 ports can be used for this procedure. Afaneh et al. ${ }^{[17]}$ describe a 5-port set up transversely across the abdominal midline. The first port is placed in the midline roughly $15 \mathrm{~cm}$ below the xiphoid process. Three additional $8-\mathrm{mm}$ robotic ports and a $5-\mathrm{mm}$ retractor port are then placed ${ }^{[17]}$. A case report in the pediatric population also describes a 4-port method ${ }^{[22]}$. We elect to use 6 ports during our procedure. Port location is shown in Figure 1. The first port is placed in the right lower quadrant using the Optiview technique with a $12-\mathrm{mm}$ port. Intraperitoneal insufflation with carbon dioxide is set to a target pressure of $15 \mathrm{mmHg}$. This $12-\mathrm{mm}$ port is used by the bedside assistant for passage of suture, suctioning, and 


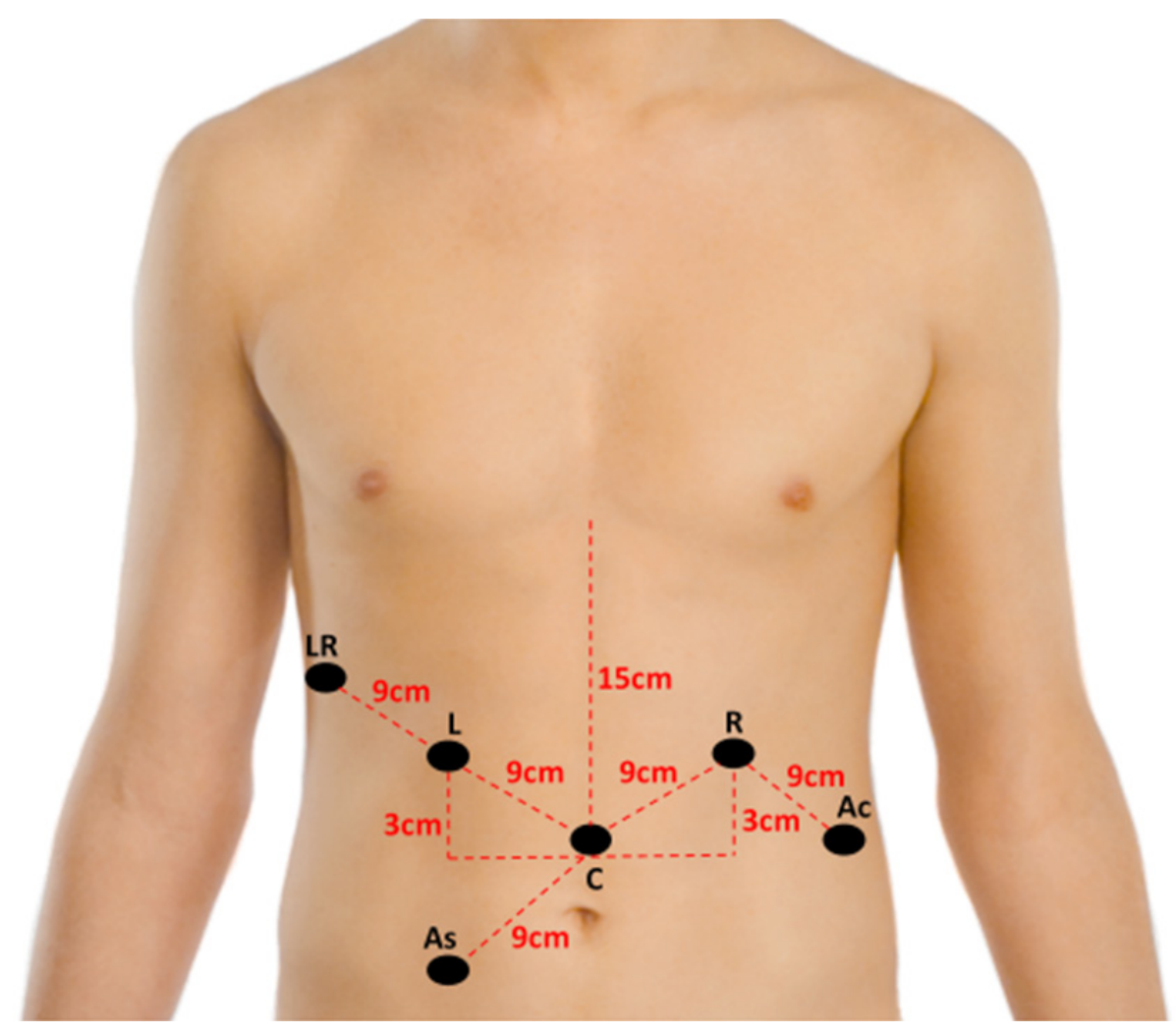

Figure 1. Location of ports for robotic Heller myotomy. LR: liver retractor port; L: port for left robotic arm (arm 1); C: camera port (arm 2); R: port for right robotic arm (arm 3); Ac: port for accessory robotic arm (arm 4); As: port for bedside assistant. Image created using public domain photo from Wikipedia Commons, 2008 ${ }^{[23]}$

rolled-up gauze pads. Four 8-mm robotic ports and a 5-mm liver retractor port are then placed. The liver retractor port is placed as laterally as possible, just under the right costal margin. This location prevents collisions between the robotic arm and the liver retractor, as opposed to the typical subxiphoid location. The patient is positioned in reverse Trendelenberg and the liver retractor put into appropriate position prior to docking. The 0-degree camera is used for the Optiview port access. A 30-degree camera is used for the rest of the operation via the robotic arm 2. Cadiere forceps are used in the left robotic arm (arm 1), and the curved bipolar dissector, vessel sealer, and fenestrated forceps are used in the right robotic arm (arm 3), while the tip-up fenestrated forceps are used in the accessory robotic arm (arm 4), which is located to the surgeon's right (patient's left) of the right robotic arm. The camera port is located $15 \mathrm{~cm}$ caudal from the xiphoid process, typically in a supraumbilical position. Arms 1, 3, and 4 are then staggered as shown in Figure 1, located $9 \mathrm{~cm}$ apart from one another. At times, in small patients, a distance of $8 \mathrm{~cm}$ between ports is required which is also acceptable. Arms 1 and 3 are located such that they are at least $3 \mathrm{~cm}$ cranial compared to the camera port, as this facilitates working high in the mediastinum.

\section{Exposure of the distal esophagus}

The operation begins with division of the gastrohepatic ligament. The area overlying the right crus is cleared off, just below the gastroesophageal junction, and extending across and dividing the phrenoesopahgeal ligament. If performing an anterior or Dor partial fundoplication, only the anterior aspect of the esophagus should be dissected to leave as much of the phrenoesophageal ligament intact. This is in contrast to a posterior or Toupet partial fundoplication where the esophagus is mobilized circumferentially by clearing the retroesophageal window. The left crus is then identified and dissected out. The method of esophageal exposure is consistent with prior literature description ${ }^{[1724-26]}$. 


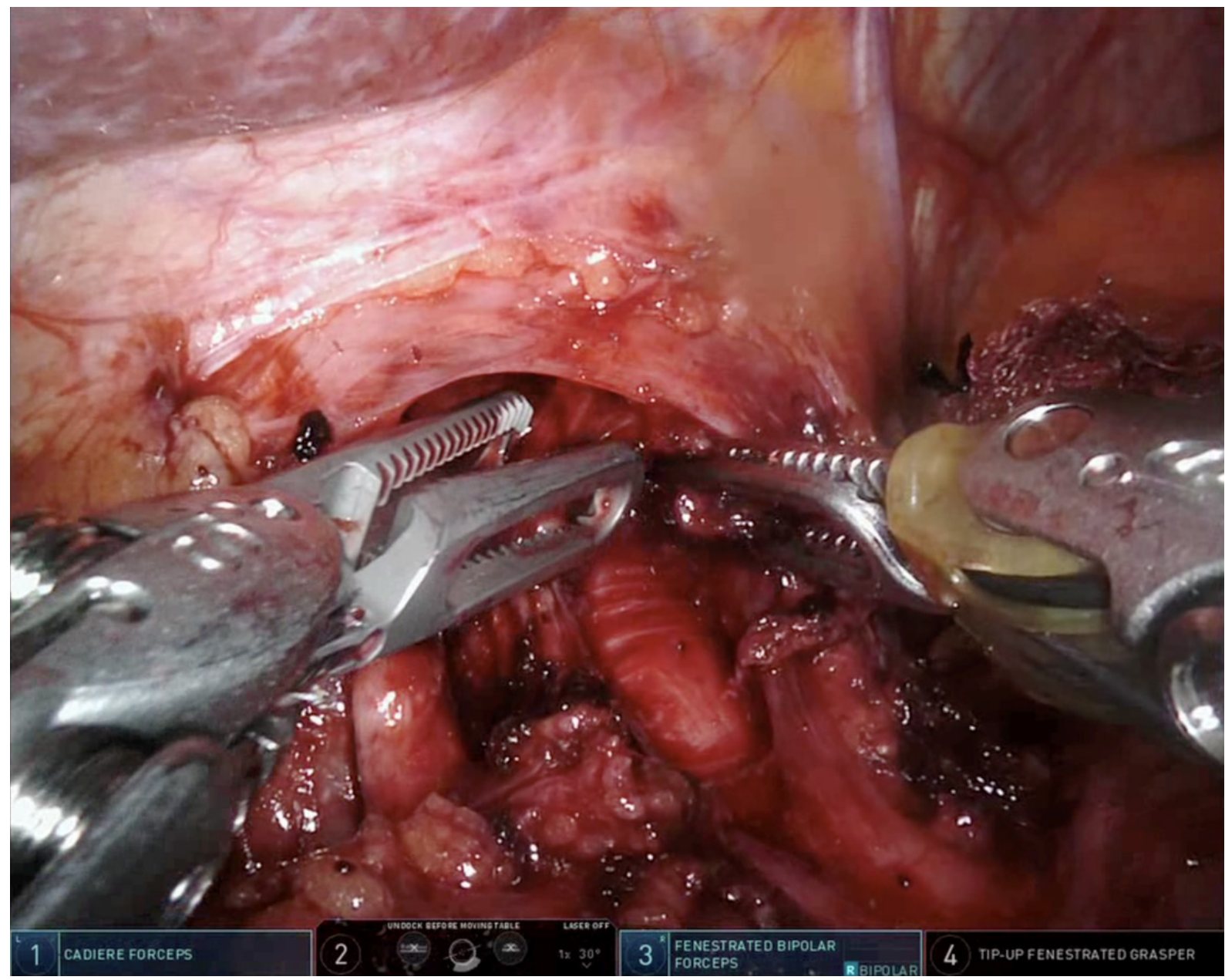

Figure 2. The use of Cadiere forceps and fenestrated bipolar forceps to perform myotomy with blunt dissection

\section{Mobilization of the gastroesophageal junction}

The periesophageal space is bluntly dissected anteriorly well up into the mediastinum. The esophagus should be mobilized for at least $8 \mathrm{~cm}$ of length. During this part of the procedure, care should be taken to identify and preserve the vagus nerve.

\section{Heller myotomy}

The myotomy usually begins between 11 and 1 o'clock on the esophageal side ${ }^{[17,26]}$. There are various techniques for creating the myotomy; we prefer to use Cadiere forceps in the left robotic arm and a fenestrated bipolar forceps in the right robotic arm to pull the fibers apart, and use electrocautery and energy near the mucosa very sparingly to avoid thermal injury [Figure 2]. The longitudinal and circular muscle fibers are divided until the submucosa underneath is exposed. This should be carried out for roughly $6-8 \mathrm{~cm}$ up into the chest and about $3 \mathrm{~cm}$ onto the stomach. It is important to disrupt any and all muscle fibers along the myotomy; at times, vessels crossing the submucosa can masquerade as muscle fibers. Special caution should be taken when extending the myotomy onto the stomach, as the differentiation between muscle fibers and submucosa is more difficult to appreciate, and the muscle fibers tend to be more adherent to the submucosa. Methylene blue is instilled into the esophageal lumen after the myotomy is complete to ensure there was no mucosal perforation. Alternatively, the patient can be placed in Trendelenburg, the esophagus and esophagogastric junction submerged under water or saline, and the esophagus insufflated to detect a leak, although this can be cumbersome unless the robotic-integrated bed 


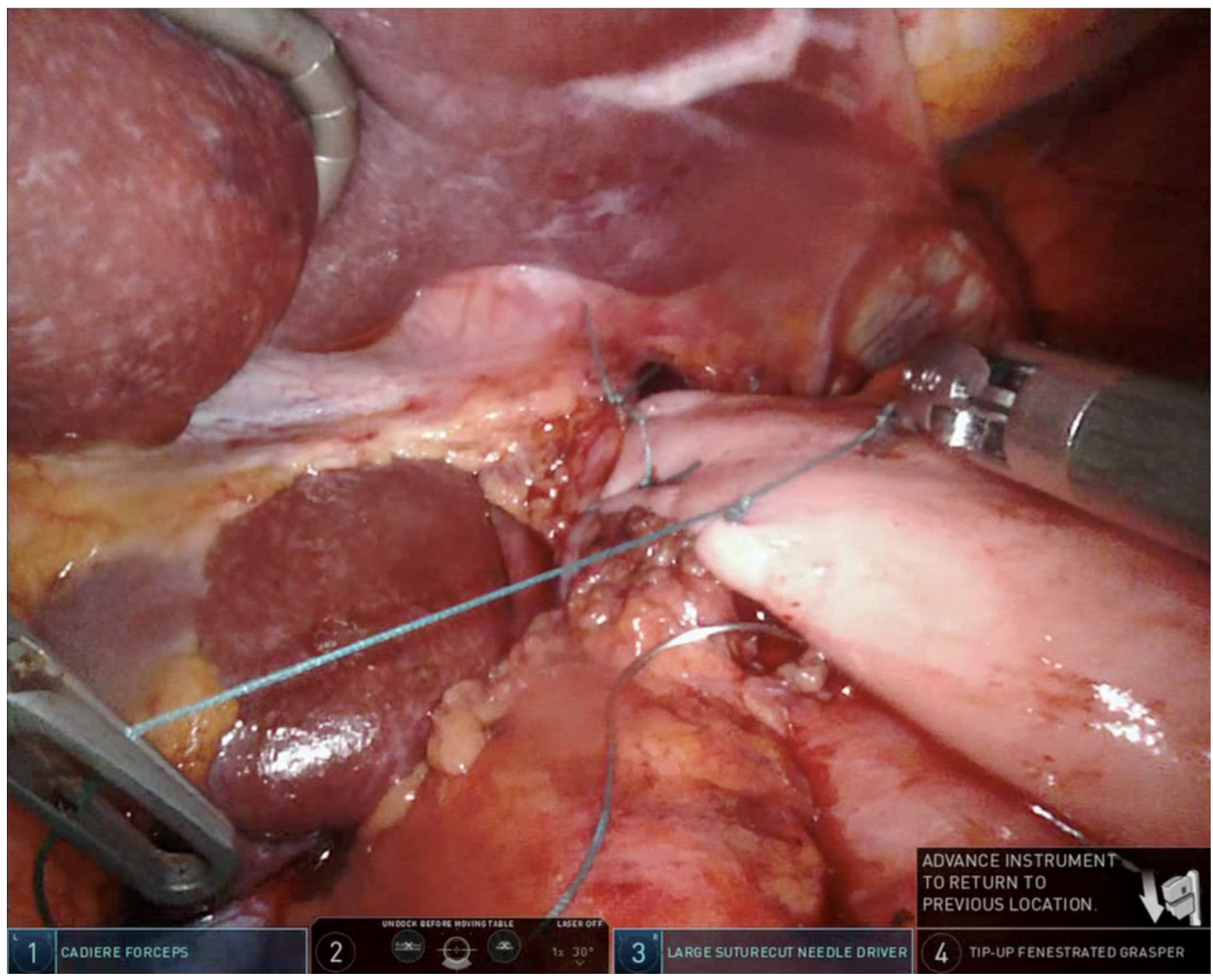

Figure 3. Completion of right-sided sutures for Dor fundoplication

is used $^{[26]}$. Previous studies have cited the utilization of endoscopic balloon inflation across the EGJ during this portion of the procedure for visualization of planes with some success ${ }^{[27]}$.

\section{Fundoplication}

In preparation for fundoplication, the stomach is retracted medially and the short gastric vessels dissected and ligated using a vessel sealer. For the Dor anterior partial fundoplication, posterior dissection is not necessary thereby avoiding injury to the posterior vague nerve. The number of stitches used and exact placement may vary by surgeon. At our institution, we first use two 2-0 Ethibond sutures to secure the fundus, esophagus and left crus together; the fundus is then rolled over the esophagogastric junction, and two 2-0 Ethibond sutures are placed similarly on the right side [Figure 3]. We avoid placing the sutures of the fundoplication too far posteriorly, so as not to overly narrow the hiatus. An additional suture may be used to secure the fundus to the diaphragm at the top of the hiatus. Studies have shown fundoplication to be a necessary part of the procedure to mitigate reflux-related symptoms ${ }^{[28]}$. The choice of Dor $v s$. Toupet fundoplication shows no significant difference in outcomes and is therefore left up to the surgeon's decision-making based on their individual experience ${ }^{[29]}$. The hypothetical benefits of the Dor are a decreased risk of dysphagia and that the fundus covers part of the myotomy and buttresses it in case a small unrecognized mucosal injury occurs. The hypothetical benefits of the Toupet are improved reflux control and that the fundoplication pulls apart the muscle edges of the myotomy, preventing it from healing together and causing recurrent symptoms. 


\section{Technical considerations}

The technical advantages of the use of robotic operative systems are mainly enhanced visualization and enhanced degree of movement available. In consideration of taking advantage of these benefits, it is important to keep your visual field free of blood ${ }^{[17]}$. This can be achieved with the proactive use of hemostatic devices to ensure vessels are coagulated prior to disruption. Additionally, it is important to ensure adequate mobilization of the gastroesophageal junction and the gastric fundus to effectively perform all steps of the procedure. Additionally, the tools utilized allow for precise dissection during the myotomy. The camera and dissectors can be used to ensure complete disruption of the LES muscle fibers ${ }^{[17]}$.

\section{Postoperative management}

Upon completion of the procedure the patient should be extubated in the operating room. When stable, they can be moved to the Post-Anesthesia Care Unite (PACU) and a postoperative chest radiograph should be obtained. If the patient is in stable condition, they can be sent to the floor from the PACU with orders for scheduled anti-emetics to prevent retching, maintenance fluids, pain management, aggressive pulmonary toilet, and a clear liquid diet. Avoiding postoperative retching is important for maintaining the integrity of tissues manipulated by the operation ${ }^{[17]}$. On postoperative day 1 , a water-soluble barium esophagram is obtained to ensure no esophageal leaks are present. Orders for the clear liquid diet should be maintained until the patient passes the postoperative swallow study. If the patient passes the swallow study, tolerating liquid diet, voiding appropriately, and if pain is controlled, he/she can be discharged as early as postoperative day 1. The patient should be allowed slow progression from full liquid to soft food diet over the next 2-4 weeks ${ }^{[27]}$. Follow-up is scheduled for 1 month. At that time, the patient can be allowed to advance diet as tolerated and resume exercise, provided there are no complications.

\section{REVIEW OF LITERATURE: ROBOTIC HELLER MYOTOMY}

Since the first published case report of an RHM in 2001, much of the literature has sought to evaluate the efficacy and safety of the robotic approach when compared to the already established laparoscopic approach. These data are summarized in Table 1. Multiple studies have compared data between LHM and RHM and revealed that there are no statistical differences in estimated blood loss $(<50 \mathrm{~mL})$, operative time, or perioperative mortality ${ }^{[13,17,20]}$. Although operative time does not show statistically significant differences, the robotic approach has been shown to be slightly longer $(122 \mathrm{~min} v s .133 \mathrm{~min})^{[13]}$. Other reports have broken down operative time relative to the number of cases performed and have shown association with improved times as the surgeon performs more cases ${ }^{[17]}$. This alludes to the potential for the robotic approach to become shorter in length as surgeons gain further experience. Although similar to LHM in many categorical results, in some studies, RHM was associated with a shorter length of hospital stay [( 1 days $v$ s. 2 days $),(2.42$ days $v$ s. 4.42 days $)]^{[13,17]}$.

When considering the operative surgical goal for achalasia, RHM is effective in achieving symptomatic relief without producing significant morbidity. Each case report indicates short-term post-operative relief of dysphagia symptoms ${ }^{[22,24,25,32]}$. Two larger studies of greater than 50 patients reported a $92.4 \%$ and $100 \%$ rate of relief for dysphagia symptoms following operation with $80 \%$ of patients needing no further intervention ${ }^{[13,27]}$. In comparison to LHM, Kim et al. ${ }^{[14]}$ suggests that the technical advantage of the robotic approach allows for a longer myotomy incision, resulting in greater durability of symptomatic relief for dysphagia. The most frequently reported long-term symptom following this procedure is reflux, which requires medication control at a rate of $62 \%$; however, this showed no significant difference compared to the laparoscopic procedure ${ }^{[13]}$.

Safety is of course the next major consideration of this operation. RHM is associated with very few postoperative or perioperative complications. The rate of esophageal mucosal perforation is of primary consideration throughout the literature. There are no noted mucosal perforations in any of the case reports 
Table 1. Summary of data from retrospective studies

\begin{tabular}{|c|c|c|c|c|c|c|}
\hline Ref. & $\begin{array}{c}\text { Type of } \\
\text { procedure }\end{array}$ & No. of patients & $\begin{array}{c}\text { Operative time } \\
\text { (min) }\end{array}$ & LOS (days) & $\begin{array}{c}\text { Risk of } \\
\text { perforation (\%) }\end{array}$ & Cost (\$) \\
\hline \multirow[t]{2}{*}{ Shaligram et al. ${ }^{[10]} 2012$} & RHM & 149 & - & $2.42 \pm 2.69$ & - & $9,415 \pm 5,515^{a}$ \\
\hline & LHM & 2116 & - & $2.70 \pm 3.87$ & - & $7,441 \pm 7,897^{\mathrm{a}}$ \\
\hline \multirow[t]{2}{*}{ Villamere et al. ${ }^{[30]} 2015$} & RHM & 314 & - & $2.26 \pm 2.05^{\mathrm{a}}$ & - & $9,258 \pm 4,278^{a}$ \\
\hline & LHM & 3135 & - & $2.78 \pm 3.55^{\mathrm{a}}$ & - & $7,425 \pm 5,693^{a}$ \\
\hline \multirow[t]{2}{*}{ Perry et al. ${ }^{[13]} 2014$} & RHM & 56 & $133 \pm 29$ & $1^{\mathrm{a}}$ & $0.0^{\mathrm{a}}$ & - \\
\hline & LHM & 19 & $121 \pm 22$ & $2^{\mathrm{a}}$ & $16.0^{\mathrm{a}}$ & - \\
\hline \multirow[t]{2}{*}{ Kim et al. ${ }^{[14]} 2019$} & RHM & 37 & 158 & 2.02 & 2.7 & - \\
\hline & LHM & 35 & 157 & 2.17 & 11.4 & - \\
\hline \multirow[t]{3}{*}{ Ali et al. ${ }^{[15]} 2019$} & RHM & 44 & $183.5^{\mathrm{a}}$ & 1 & $0.0^{\mathrm{a}}$ & - \\
\hline & LHM & 40 & $157^{\mathrm{a}}$ & 1 & $15.0^{\mathrm{a}}$ & - \\
\hline & POEM & 87 & 169 & 1 & 1.1 & - \\
\hline \multirow[t]{2}{*}{ Huffmanm et al. ${ }^{[18]} 2007$} & $\mathrm{RHM}$ & 24 & $355 \pm 23^{\ddagger}$ & 2.8 & 0.0 & - \\
\hline & LHM & 37 & $287 \pm 9^{\ddagger}$ & 2.6 & 8.1 & - \\
\hline \multirow[t]{2}{*}{ Khashab et al. ${ }^{[21]} 2017$} & RHM & 52 & $263^{b}$ & 2.3 & 0.0 & $17,782^{b}$ \\
\hline & POEM & 52 & $106^{b}$ & 1.9 & 7.7 & $14,481^{b}$ \\
\hline Pallabazzer et al. ${ }^{[27]} 2020$ & RHM & 66 & $161.4 \pm 40.2$ & - & - & - \\
\hline Saurabh et al..$^{[31]} 2014$ & RHM & 12 & 150 & 1.5 & - & - \\
\hline
\end{tabular}

Meta-analyses, case reports, and case series not included in this chart. ${ }^{a}$ Indicates that there was statistically significant difference $(P$ $<0.05)$ in data when RHM was compared to LHM; ${ }^{b}$ Indicates that there was statistically significant difference $(P<0.05)$ in data when RHM was compared to POEM; ${ }^{\dagger}$ operative time for this study was measured as time of anesthesia induction to extubation. LOS: length of stay; RHM: robotic Heller myotomy; LHM: laparoscopic Heller myotomy; POEM: per oral endoscopic myotomy

and only 1 perforation noted in the retrospective reviews ${ }^{[14,15,21,22,24,25,27,32]}$. In a review of the progression of the role of myotomy, Allaix and Patti ${ }^{[33]}$ highlight two separate studies that show rates of mucosal perforation in LHM being $16 \%$ and $8 \%$, while the RHM groups had a $0 \%$ perforation rate in both studies. A meta-analysis further confirmed the safety of RHM in view of the significantly fewer mucosal injuries, and stated that it is safer than the laparoscopic approach ${ }^{[20]}$. As mucosal perforation leads to greater perioperative morbidity, the evidence reported in these studies should be strongly considered when thinking of the safety of the patient in choosing the operative approach.

The technical advantages to this procedure are believed to be associated with the enhanced 3-D visualization and the increased degree of movement of the surgical instruments with robotic systems ${ }^{[13,31,34]}$. The enhanced visualization and increased precision of control are believed to contribute to having fewer mucosal perforations and to the ability to make longer incisions for the myotomy ${ }^{[13,14,31]}$. In consideration of disadvantages of robotic operations, multiple studies cite cost. The cost analyses performed show statistically significant higher cost when comparing RHM to LHM, with one study citing as much as a $21 \%$ increase when comparing robotic to laparoscopic surgeries ${ }^{[17,19,21,30]}$. One multicenter study demonstrated that LHM was significantly less expensive than RHM $(\$ 7,441 \text { vs. } \$ 9,415, P=0.0028)^{[10]}$; another found a similar difference $(\$ 7,425 \text { for LHM } v \text { s. } \$ 9,258 \text { for RHM, } P<0.05)^{[30]}$. Further efforts should be made to analyze cost associated with robotic procedures and discover ways to mitigate charges to help overcome this barrier.

Most of the research on RHM is retrospective in nature and with small cohorts, posing some limitations regarding prospective application of the data. However, enough evidence has been derived from these studies to provide grounds for further investigation. Future randomized control studies are needed for confirmation of suspected outcomes.

\section{CONCLUSION}

RHM with Dor (or Toupet) fundoplication is an extremely safe and effective procedure for relieving symptoms of esophageal achalasia. Use of this approach is associated with almost no complications related 
to esophageal perforations. In our experience of 50 patients undergoing this operation, we experienced a $0 \%$ perforation rate, median hospital stay of 1 day (range 1-3 days), median operation duration of 143 min (range 84-301 min), and median blood loss of $25 \mathrm{~mL}$ (range 5-100 mL). Enhanced 3-D visualization and increased mobility of surgical instruments provide surgeons with superior dexterity for performance of intricate movements required for the dissection of the lower esophageal sphincter. The most frequently reported postoperative symptom is reflux requiring pharmacologic management. The largest barrier for this procedure remains the high cost. Limitations to the knowledge of this procedure include the make-up of the literature being either case reports or retrospective studies. With the advent of POEM, the future role of RHM remains unclear, as patients often prefer a procedure that is perceived to be less invasive. Advantages of POEM compared to RHM is the absence of incisions and, in experienced hands, shorter operative time; on the other hand, RHM permits the addition of a fundoplication to mitigate reflux ${ }^{[35]}$. The hospital length of stay and postoperative pain has been demonstrated to be similar between the two procedures ${ }^{[36]}$. The advantages and disadvantages of RHM should be investigated with comparative studies and, ideally, randomized control trials.

\section{DECLARATIONS}

\section{Authors' contributions}

Performed literature review, contributed to manuscript writing: Sollie ZW

Contributed to manuscript writing: Jiwani AZ

Project oversight, author of techniques, contributed to manuscript writing: Wei B

\section{Availability of data and materials}

Not applicable.

\section{Financial support and sponsorship}

None.

\section{Conflicts of interest}

All authors declared that there are no conflicts of interest.

\section{Ethical approval and consent to participate}

Not applicable.

\section{Consent for publication}

Not applicable.

\section{Copyright}

(c) The Author(s) 2020.

\section{REFERENCES}

1. Gennaro N, Portale G, Gallo C, et al. Esophageal achalasia in the Veneto region: epidemiology and treatment. Epidemiology and treatment of achalasia. J Gastrointest Surg 2011;15:423-8.

2. Howard PJ, Maher L, Pryde A, Cameron EW, Heading RC. Five year prospective study of the incidence, clinical features, and diagnosis of achalasia in Edinburgh. Gut 1992;33:1011-5.

3. O'Neill OM, Johnston BT, Coleman HG. Achalasia: a review of clinical diagnosis, epidemiology, treatment and outcomes. World $J$ Gastroenterol 2013;19:5806-12.

4. Podas T, Eaden J, Mayberry M, Mayberry J. Achalasia: a critical review of epidemiological studies. Am J Gastroenterol 1998;93:2345-7.

5. Ho KY, Tay HH, Kang JY. A prospective study of the clinical features, manometric findings, incidence and prevalence of achalasia in Singapore. J Gastroenterol Hepatol 1999;14:791-5.

6. Farrukh A, DeCaestecker J, Mayberry JF. An epidemiological study of achalasia among the South Asian population of Leicester, 1986- 
2005. Dysphagia 2008;23:161-4

7. Pandolfino JE, Kahrilas PJ. Presentation, diagnosis, and management of achalasia. Clin Gastroenterol Hepatol 2013;11:887-97.

8. Mirsharifi A, Ghorbani Abdehgah A, Mirsharifi R, et al. Laparoscopic Heller myotomy for achalasia: experience from a single referral tertiary center. Middle East J Dig Dis 2019;11:90-7.

9. Sánchez A, Rodríguez O, Nakhal E, et al. Robotic-assisted Heller myotomy versus laparoscopic Heller myotomy for the treatment of esophageal achalasia: a case-control study. J Robot Surg 2012;6:213-6.

10. Shaligram A, Unnirevi J, Simorov A, Kothari VM, Oleynikov D. How does the robot affect outcomes? A retrospective review of open, laparoscopic, and robotic Heller myotomy for achalasia. Surg Endosc 2012;26:1047-50.

11. Campos GM, Vittinghoff E, Rabl C, et al. Endoscopic and surgical treatments for achalasia: a systematic review and meta-analysis. Ann Surg 2009;249:45-57.

12. Hung YC, Westfal ML, Chang DC, Kelleher CM. Heller myotomy is the optimal index procedure for esophageal achalasia in adolescents and young adults. Surg Endosc 2019;33:3355-60.

13. Perry KA, Kanji A, Drosdeck JM, et al. Efficacy and durability of robotic Heller myotomy for achalasia: patient symptoms and satisfaction at long-term follow-up. Surg Endosc 2014;28:3162-7.

14. Kim SS, Guillen-Rodriguez J, Little AG. Optimal surgical intervention for achalasia: laparoscopic or robotic approach. J Robot Surg 2019;13:397-400.

15. Ali AB, Khan NA, Nguyen DT, et al. Robotic and per-oral endoscopic myotomy have fewer technical complications compared to laparoscopic Heller myotomy. Surg Endosc 2020;34:3191-6.

16. Melvin WS, Needleman BJ, Krause KR, et al. Computer-assisted robotic Heller myotomy: initial case report. J Laparoendosc Adv Surg Tech A 2001;11:251-3.

17. Afaneh C, Finnerty B, Abelson JS, Zarnegar R. Robotic-assisted Heller myotomy: a modern technique and review of outcomes. $J$ Robot Surg 2015;9:101-8.

18. Huffmanm LC, Pandalai PK, Boulton BJ, et al. Robotic Heller myotomy: a safe operation with higher postoperative quality-of-life indices. Surgery 2007;142:613-8; discussion 618-20.

19. Falkenback D, Lehane CW, Lord RV. Robot-assisted oesophageal and gastric surgery for benign disease: antireflux operations and Heller's myotomy. ANZ J Surg 2015;85:113-20.

20. Milone M, Manigrasso M, Vertaldi S, et al. Robotic versus laparoscopic approach to treat symptomatic achalasia: systematic review with meta-analysis. Dis Esophagus 2019;32:1-8.

21. Khashab MA, Kumbhari V, Tieu AH, et al. Peroral endoscopic myotomy achieves similar clinical response but incurs lesser charges compared to robotic heller myotomy. Saudi J Gastroenterol 2017;23:91-6.

22. Ballouhey Q, Dib N, Binet A, et al. How robotic-assisted surgery can decrease the risk of mucosal tear during Heller myotomy procedure? J Robot Surg 2017;11:255-8.

23. Haggstrom M. Upper Body Front. Wikipedia Commons. Published November 7, 2008. Available from: https://commons.wikimedia.org/ wiki/File:Upper_body_front.png. [Last accessed on 2 Oct 2020]

24. Masrur M, Gonzalez-Ciccarelli LF, Giulianotti PC. Robotic Heller myotomy for achalasia after laparoscopic Roux-en-Y gastric bypass: a case report and literature review. Surg Obes Relat Dis 2016;12:1755-7.

25. Altokhais T, Mandora H, Al-Qahtani A, Al-Bassam A. Robot-assisted Heller's myotomy for achalasia in children. Comput Assist Surg (Abingdon) 2016;21:127-31.

26. Damani T, Ballantyne G. Robotic foregut surgery. Surg Clin North Am 2020;100:249-64.

27. Pallabazzer G, Peluso C, de Bortoli N, et al. Clinical and pathophysiological outcomes of the robotic-assisted Heller-Dor myotomy for achalasia: a single-center experience. J Robot Surg 2020;14:331-5.

28. Di Corpo M, Farrell TM, Patti MG. Laparoscopic Heller myotomy: a fundoplication is necessary to control gastroesophageal reflux. $J$ Laparoendosc Adv Surg Tech A 2019;29:721-5.

29. Aiolfi A, Tornese S, Bonitta G, et al. Dor versus Toupet fundoplication after laparoscopic Heller myotomy: systematic review and Bayesian meta-analysis of randomized controlled trials. Asian J Surg 2020;43:20-8.

30. Villamere J, Gebhart A, Vu S, Nguyen NT. Utilization and outcome of laparoscopic versus robotic general and bariatric surgical procedures at academic medical centers. Surg Endosc 2015;29:1729-36.

31. Saurabh S, Unger E, Grossman J, et al. Role of robotic-assisted surgery in benign esophageal diseases. J Robot Surg 2014;8:105-9.

32. Zilberstein B, Franciss MY, Genovesi A, et al. Pioneer robotic Serra-Doria operation for recurrent achalasia after Heller's cardiomyotomy: a "New Quondam" procedure. J Laparoendosc Adv Surg Tech A 2017;27:524-8.

33. Allaix ME, Patti MG. Heller myotomy for achalasia. From the open to the laparoscopic approach. World J Surg 2015;39:1603-7.

34. Toro JP, Lin E, Patel AD. Review of robotics in foregut and bariatric surgery. Surg Endosc 2015;29:1-8.

35. Repici A, Fuccio L, Maselli R, et al. GERD after per-oral endoscopic myotomy as compared with Heller's myotomy with fundoplication: a systematic review with meta-analysis. Gastrointest Endosc 2018;87:934-43.

36. Awaiz A, Yunus RM, Khan S, Memon B, Memon MA. Systematic review and meta-analysis of perioperative outcomes of peroral endoscopic myotomy (POEM) and laparoscopic Heller myotomy (LHM) for achalasia. Surg Laparosc Endosc Percutan Tech 2017;27:123-31. 